\title{
Health status and labor force participation: evidence for urban low and middle income individuals in Colombia
}

\author{
Ana María Iregui-Bohórquez ${ }^{1}$ \& Ligia Alba Melo-Becerra ${ }^{1}$ \& \\ María Teresa Ramírez-Giraldo ${ }^{1}$
}

Received: 18 February 2015 / Accepted: 16 February 2016/Published online: 26 February 2016

\# ISEG 2016

\begin{abstract}
This paper analyzes the relationship between individual health status and labor force participation using the first wave of the Colombian Longitudinal Survey. The empirical modeling strategy accounts for the presence of potential endogeneity between these two variables. The results show that there is a positive relationship between health and labor force participation in both directions, indicating that better health is likely to lead to a higher probability of participation in the labor market, but also that individuals who participate in the labor market are more likely to report better health. Interesting differences are uncovered when comparing the results by gender and/or age groups. For instance, for younger females, health status and higher education positively affect the probability of labor participation, whereas having children under the age of 5 and being married reduce their probability of participation. Our findings also highlight the importance of public policy to guarantee good health conditions of the population which could also have a positive impact on labor productivity and consequently on long-run economic growth.
\end{abstract}

Keywords Health status - Labor force participation - Endogeneity · Two-stage least squares $\cdot$ Ordered probit

JEL Classification $\mathrm{C} 35 \cdot \mathrm{C} 36 \cdot \mathrm{I} 10 \cdot \mathrm{J} 21$

Ana María Iregui-Bohórquez

airegubo@banrep.gov.co

1 Banco de la República, Carrera 7 No. 14-78, piso 11, Bogotá, Colombia 